\title{
BMJ Open Antihypertensive therapies in moderate or severe aortic stenosis: a systematic review and meta-analysis
}

\author{
Jonathan Sen, ${ }^{1,2}$ Erin Chung, ${ }^{3}$ Christopher Neil, ${ }^{1,2}$ Thomas Marwick (D) ${ }^{1,2}$
}

To cite: Sen J, Chung E, Neil C, et al. Antihypertensive therapies in moderate or severe aortic stenosis: a systematic review and meta-analysis. BMJ Open 2020;10:e036960. doi:10.1136/ bmjopen-2020-036960

- Prepublication history and additional material for this paper are available online. To view these files, please visit the journal online (http://dx.doi org/10.1136/bmjopen-2020036960).

Received 15 January 2020 Revised 19 August 2020 Accepted 25 August 2020

\section{Check for updates}

(C) Author(s) (or their employer(s)) 2020. Re-use permitted under CC BY-NC. No commercial re-use. See rights and permissions. Published by BMJ.

${ }^{1}$ Baker Heart and Diabetes Institute, Melbourne, Victoria, Australia

${ }^{2}$ Faculty of Medicine, Dentistry and Health Sciences, University of Melbourne, Melbourne,

Victoria, Australia

${ }^{3}$ Graduate Department of Pharmaceutical Sciences, University of Toronto, Toronto, Ontario, Canada

Correspondence to

Dr Thomas Marwick;

tom.marwick@bakeridi.edu.au

\section{ABSTRACT}

Background Hypertension confers a poor prognosis in moderate or severe aortic stenosis (AS), however, antihypertensive therapy (AHT) is often not prescribed due to the perceived deleterious effects of vasodilation and negative inotropes.

Objective To assess the efficacy and safety outcomes of AHT in adults with moderate or severe AS.

Design Systematic review and meta-analysis.

Data sources The Cochrane Central Register of Controlled Trials, MEDLINE, EMBASE and grey literature were searched without language restrictions up to 9 September 2019.

Study eligibility criteria, appraisal and synthesis methods Two independent reviewers performed screening, data extraction and risk of bias assessments from a systematic search of observational studies and randomised controlled trials comparing $\mathrm{AHT}$ with a placebo or no AHT in adults with moderate or severe AS for any parameter of efficacy and safety outcomes. Conflicts were resolved by the third reviewer. Meta-analysis with pooled effect sizes using random-effects model, were estimated in $R$.

Main outcome measures Mortality, Left Ventricular (LV) Mass Index, systolic blood pressure, diastolic blood pressure and LV ejection fraction

Results From 3025 publications, 31 studies (26500 patients) were included in the qualitative synthesis and 24 studies in the meta-analysis. AHT was not associated with mortality when all studies were pooled, but heterogeneity was substantial across studies. The effect size of AHT differed according to drug class. Renin-angiotensinaldosterone system inhibitors (RAASi) were associated with reduced risk of mortality (Pooled HR $0.58,95 \% \mathrm{Cl}$ 0.43 to $0.80, p=0.006$ ), The differences in changes of haemodynamic or echocardiographic parameters from baseline with and without AHT did not reach statistical significance.

Conclusion AHT appears safe, is well tolerated. RAASi were associated with clinical benefit in patients with moderate or severe AS.

\section{INTRODUCTION}

Aortic stenosis (AS) is common and of increasing prevalence. ${ }^{1}$ AS is recognised as both a heart valve disease and a disease of the left ventricular (LV), ${ }^{2}$ because LV remodelling or LV hypertrophy (LVH) occur as an

\section{Strengths and limitations of this study}

The most comprehensive review of evidence to date, summarising the results of observational studies and randomised controlled trials in all relevant databases, involving over 20000 participants.

- As there are few randomised trials, most publications derived from non-randomised observational studies, and there is a risk of selection, information and confounding bias.

- Classification of moderate or severe aortic stenosis (AS) varied in different studies; some defined participants on the basis of undergoing aortic valve replacement.

- For those studies that classified severity of AS by echo parameters, a wide range of thresholds were used, such as aortic valve area less than $0.75,0.8$, 1 or $1.2 \mathrm{~cm}^{2}$ or peak velocity above $2.5,3,4.5$ or $5 \mathrm{~m} / \mathrm{s}$.

- There was variability in antihypertensive therapy treatments and controls.

adaptive response to compensate for $\mathrm{LV}$ afterload and in order to normalise wall stress. ${ }^{34}$ Since LVH is associated with impaired coronary blood flow reserve, diastolic dysfunction and increased risk of heart failure and death, ${ }^{5-12}$ this may also be an important contributor to the symptoms and mortality associated with AS. ${ }^{5613-18}$ However, pressure overload due to hypertension also may result in increased LV mass, mask pressure gradient and lead to low-gradient severe AS. ${ }^{19-21}$ Globally, the ageing population has led to an increased prevalence of hypertension, and the combination of AS and hypertension can accelerate need for aortic valve replacement (AVR) ${ }^{22-30}$ Consequently, $\mathrm{LVH}$ regression is a potential therapeutic target in AS.

Current guidelines recommend treating hypertension in $\mathrm{AS}^{31}{ }^{32}$ and inhibition of renin-angiotensin and aldosterone systems (RAAS) may have benefits on LV remodelling. ${ }^{33}$ Nonetheless, current drug monographs state that antihypertensive therapies (AHT) should be used with caution in patients 
with significant AS and are commonly not prescribed to patients with moderate or severe AS. The two most widely cited concerns are the dependence of coronary flow on aortic pressure in $\mathrm{LVH}$, and the need to preserve $\mathrm{LV}$ preload to fill the hypertrophied LV and maintain cardiac output. ${ }^{34}$ Other potential concerns of AHT in AS include vasodilation, negative inotropes, hypotension, fall in filling pressure and syncope. In this systematic review and meta-analysis, we assessed the effects (clinical outcomes, haemodynamic and echocardiographic changes) of AHT in patients with moderate or severe AS from observational studies and randomised controlled trials (RCTs). We hypothesised that AHT can be used effectively and safely for treating hypertension in moderate or severe AS.

\section{METHODS}

This systematic review was carried out in accordance with the Preferred Reporting Items for Systematic Reviews and Meta-Analyses Statement and Meta-analyses Of Observational Studies in Epidemiology Checklist. ${ }^{35} 36$

\section{Search strategy}

We searched the Cochrane Central Register of Controlled Trials (up to 9 September 2019), MEDLINE (1946 to 9 September 2019) and EMBASE (1947 to 9 September 2019) for RCTs and observational studies that assessed the use of any AHT in patients over 18 years old with moderate or severe AS. Common search terms included: ("aortic valve stenosis" or "aortic stenosis") and ("antihypertensive agents" or "angiotensin converting enzyme antagonist" or "angiotensin receptor-2 blocker" or "diuretic" or other drug classes or other specific drug names). We also handsearched relevant cardiology journals, conference proceedings and clinical trials databases and reference lists of relevant articles, including reviews. Language, publication status and length of follow-up restrictions were not applied. The full MEDLINE search strategy and list of grey literature are contained within the online supplemental materials. EndNote (V.X9.3.2, Clarivate Analytics, Philadelphia, USA) was used to retrieve citations.

\section{Study selection}

Two reviewers (JS and EC) independently screened articles for inclusion based on the following criteria: adults (over 18 years old) with moderate or severe AS, treated with any AHT and assessed for any parameter of efficacy (eg, survival, reduction in blood pressure, improvement in LV function) and safety outcomes (eg, mortality, renal impairment). Studies were excluded did not describe AS severity grade, had a sample size less than six patients or if abstracts or unpublished studies were not methodological quality-assessable and critically appraisable. Bibliographies of review articles were analysed for additional articles but excluded for the purposes of the study. Systemic review management software (Covidence,
Melbourne, Australia) was used to track papers. Conflicts were resolved by consensus with a third reviewer (TM).

\section{Data extraction}

Data extraction was done by two independent reviewers (JS and EC) using standard forms. Any disagreements and conflicts were resolved by a third reviewer (TM). The variables extracted are described in online supplemental materials. Post-treatment values and/or change from baseline (mean and SD, effect estimates and 95\% CI or number and proportions) were recorded for the primary outcome, mortality, and secondary outcomes, LV mass index, systolic blood pressure, diastolic blood pressure and LV ejection fraction. Other outcomes extracted included post-AVR complications such as atrial fibrillation, stroke, need for permanent pacemaker, readmission or acute kidney disease and other haemodynamic or echocardiographic parameters such as mean atrial pressure, heart rate, aortic valve area, mean pressure gradient, deceleration time, $\mathrm{E} / \mathrm{A}$ ratio and $\mathrm{E} / \mathrm{e}$ ' ratio. The authors of included studies were contacted for clarification, when needed.

\section{Risk of bias and quality assessments}

Risk of bias assessments were conducted independently by two reviewers (JS and EC) using the Cochrane Collaboration tool for RCTs (which include judgement of bias from random sequence generation, allocation concealment, blinding of participants and personnel, assessments should be made for each main outcome, blinding of outcome assessment, incomplete outcome data and selective reporting). Quality of non-randomised casecontrol and cohort studies were assessed using NewcastleOttawa Scale (which include assessment of patient selection, comparability and outcomes), while quality of uncontrolled observational studies was assessed based on National Heart, Lung and Blood Institute Study Quality Assessment Tool for Before-After Studies with No Control Group.

\section{Data syntheses and analyses}

Dichotomous outcomes (alive vs dead at follow-up) were expressed as numbers, proportions and relative risks (RR), time-to-event outcomes (mortality) were expressed as HRs with $95 \% \mathrm{CI}$, while continuous outcomes were expressed as means and SD, and standardised mean differences. Meta-analyses were performed to pool data and to obtain overall effect sizes using a random-effects model. Event rate data were available for mortality and were pooled to determine effect size as RR. For other continuous outcomes, standardised mean differences were determined from taking the means and SD of the intervention and control groups. A two-sided $\mathrm{p}<0.05$ was considered statistically significant. Additional subgroup analyses were done separately according to study design (observational studies or RCTs), drug class, presence of AVR, country, age, severe AS only and LV ejection fraction (LVEF), if each subgroup has more than one 
study. Heterogeneity between studies was tested for each outcome using $\mathrm{I}^{2}$ statistic (where $0 \%-40 \%$ is not important, $30 \%-60 \%$ is moderate, $50 \%-90 \%$ is substantial and $75 \%-100 \%$ is considerable). ${ }^{37}$ Funnel plots, Egger test and p curve analyses were used to assess publication bias. ${ }^{38}$ All statistical analyses were conducted in $\mathrm{R}$ (R Project for Statistical Computing, V.3.5.3) ${ }^{39}$

\section{Public and patient involvement}

This systematic review arose from clinical observation and discussion with individual patients with AS, but there was no systematic public involvement in the research process, design of and interpretation of results from this systematic review. However, the findings of this review will be shared with members of the public, patient and other healthcare professionals via news and educational meetings.

\section{RESULTS}

\section{Search results and study characteristics}

Among 3025 unique citations screened, 31 studies $(\mathrm{n}=26500),{ }^{21}{ }^{40-72}$ consisting of eight RCTs, 16 cohort, one cross-over and six uncontrolled studies, were included in the qualitative analysis, and 24 studies were included in the meta-analysis (figure 1). Study characteristics are summarised in table 1. Sample sizes ranged from 15 to 15896 patients. The follow-up period was at least 1 year for $50 \%$ of the studies. The clinical effect of RAAS inhibitors (RAASi) was assessed in 19/30 (63.3\%), nitroprusside in 4/30 (13\%-all uncontrolled studies), beta-blockers (BB) in $3 / 31(9.7 \%)$, calcium channel blocker (CCB) in $1 / 31(3.2 \%)$, frusemide in $1 / 31(3.2 \%)$, RAASi or BB in $2 / 31(6.5 \%)$ and RAASi or BB or diuretics in $1 / 31(3.2 \%)$ of studies. Clinical outcomes of AHT following transcatheter AVR, surgical AVR and without AVR were explored in $26.7 \%, 13.3 \%$ and $60 \%$ of studies, respectively.

\section{Patient characteristics}

Baseline patient characteristics of each study are summarised in tables 2 and 3. Overall, the mean age was $83.7 \pm 7.9$ years, there were 11960 females $(47.2 \%)$, and $70.6 \%$ of patients had New York Heart Association (NYHA) class III or IV heart failure. Common comorbidities were dyslipidaemia $(54.3 \%)$, diabetes $(34.3 \%)$, coronary artery disease $(35.5 \%)$, atrial fibrillation $(34.3 \%)$, moderate or
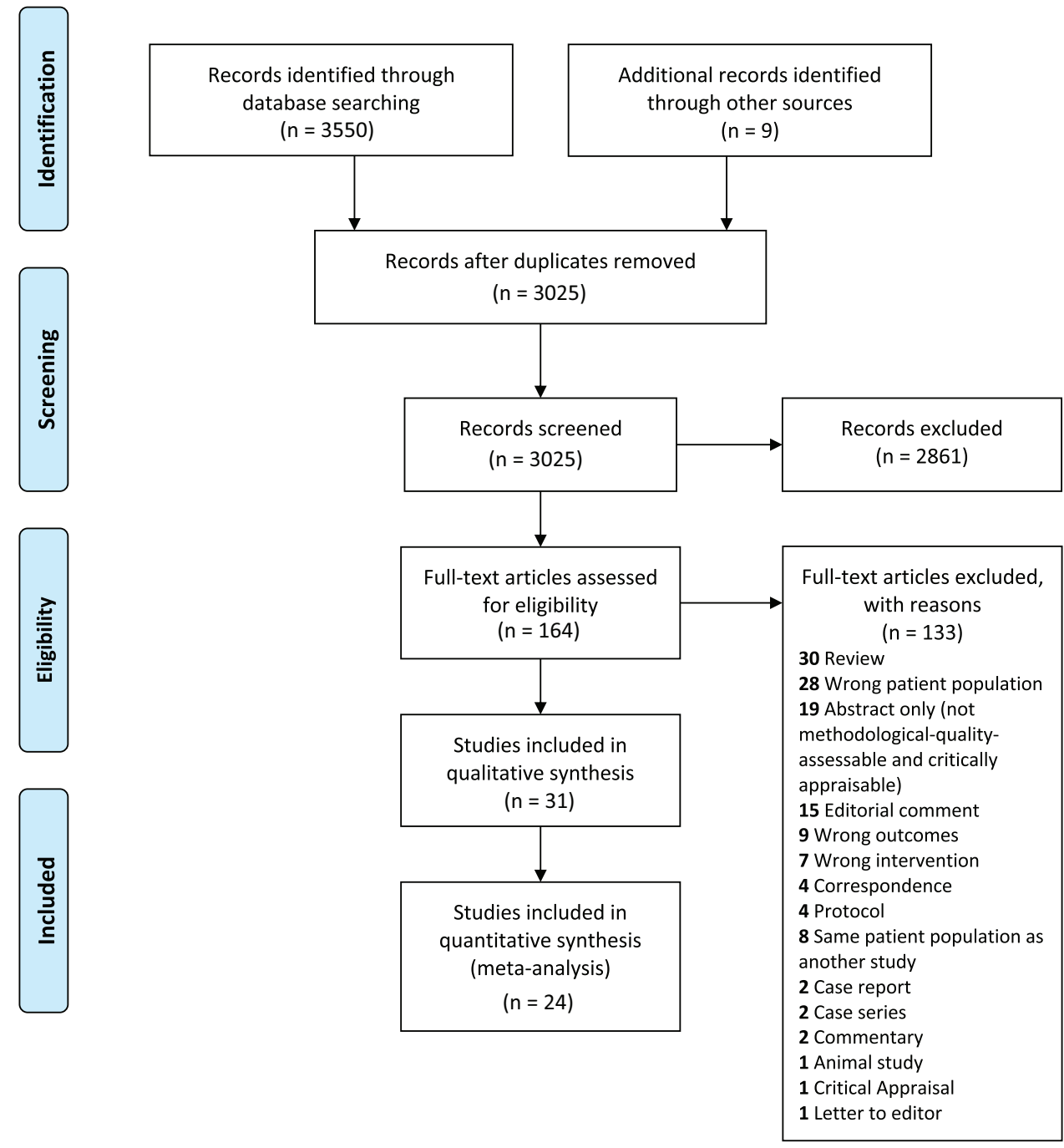

Figure 1 Flow diagram of study selection. 


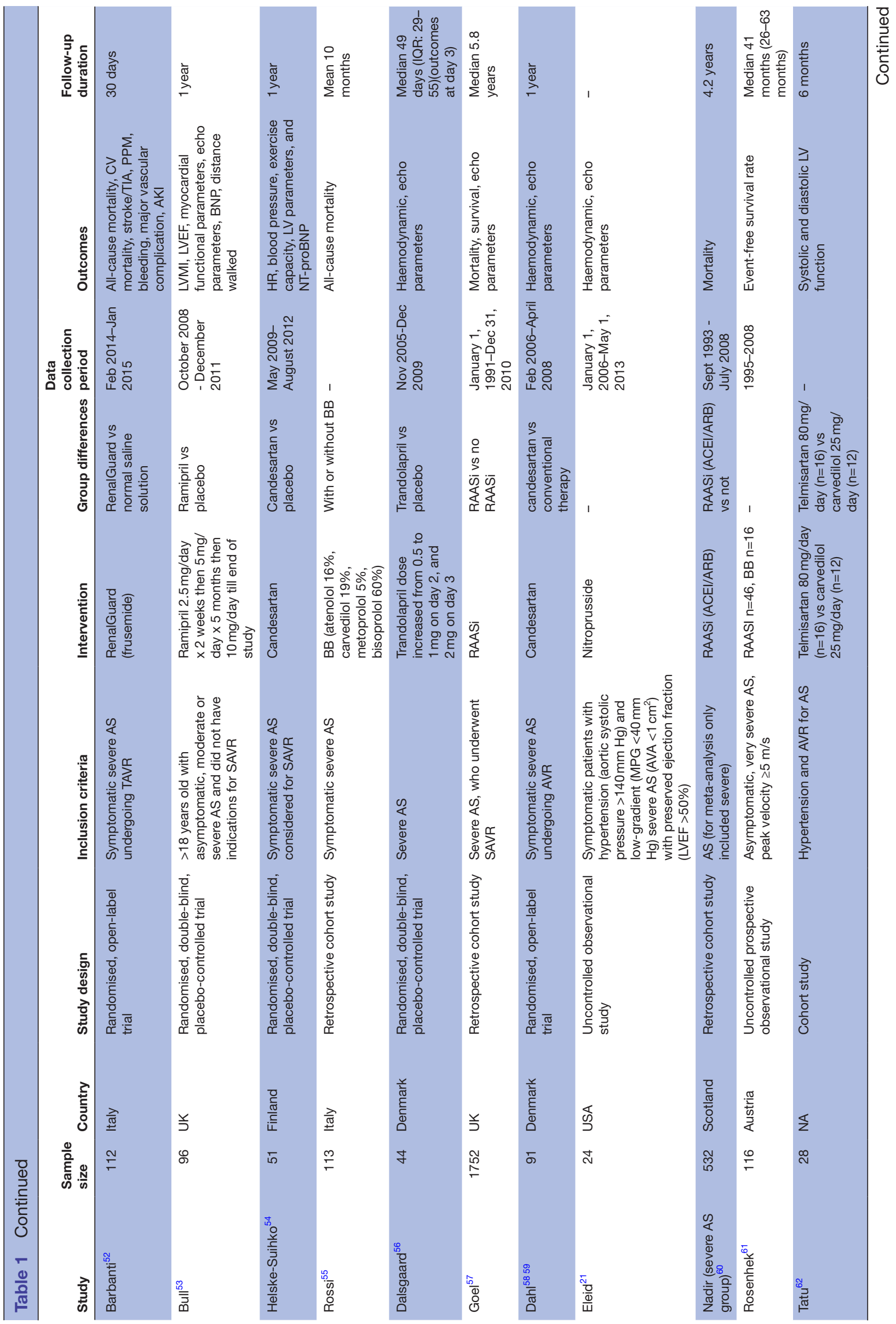

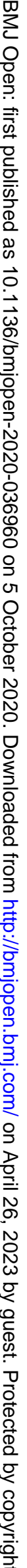









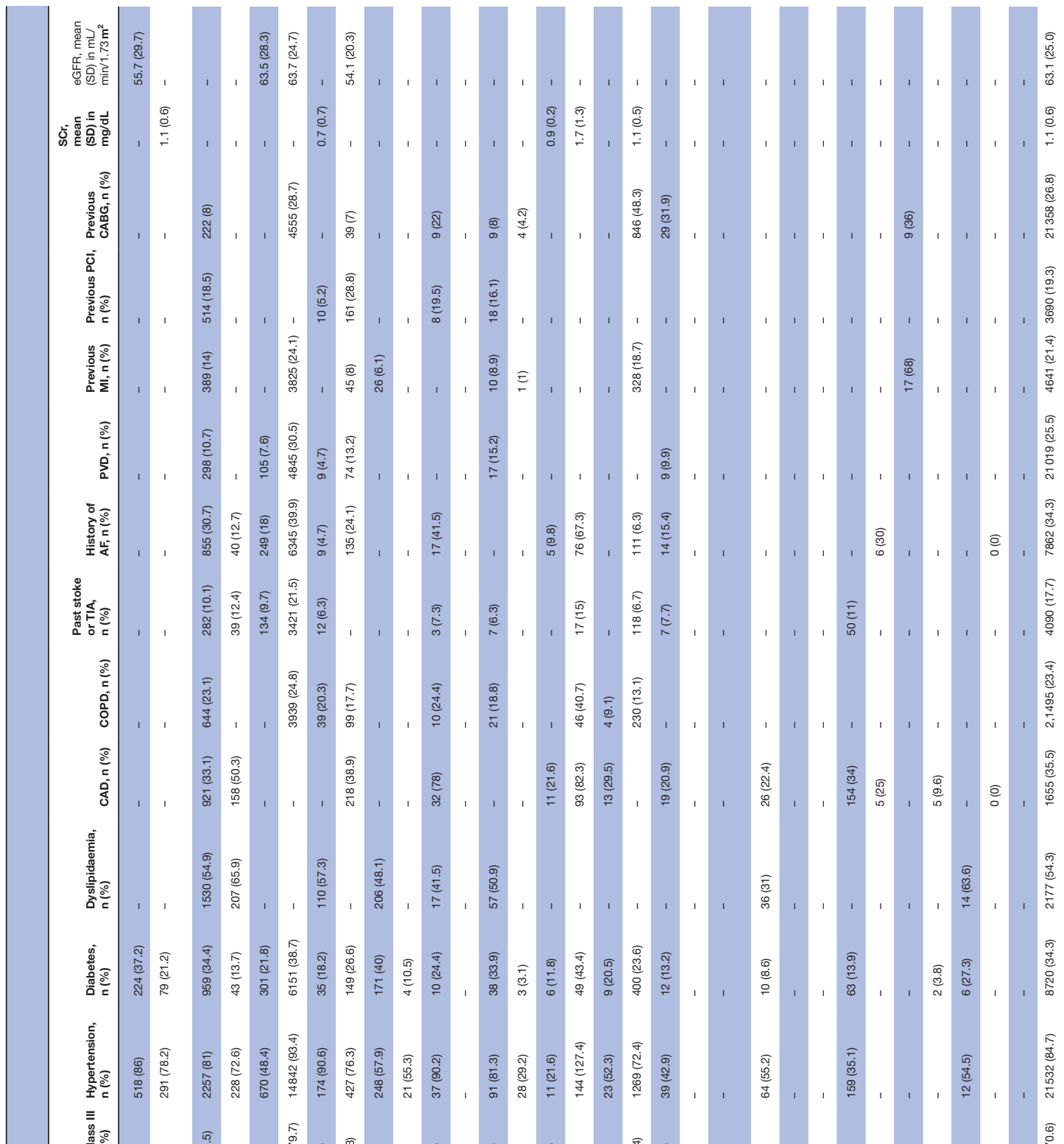




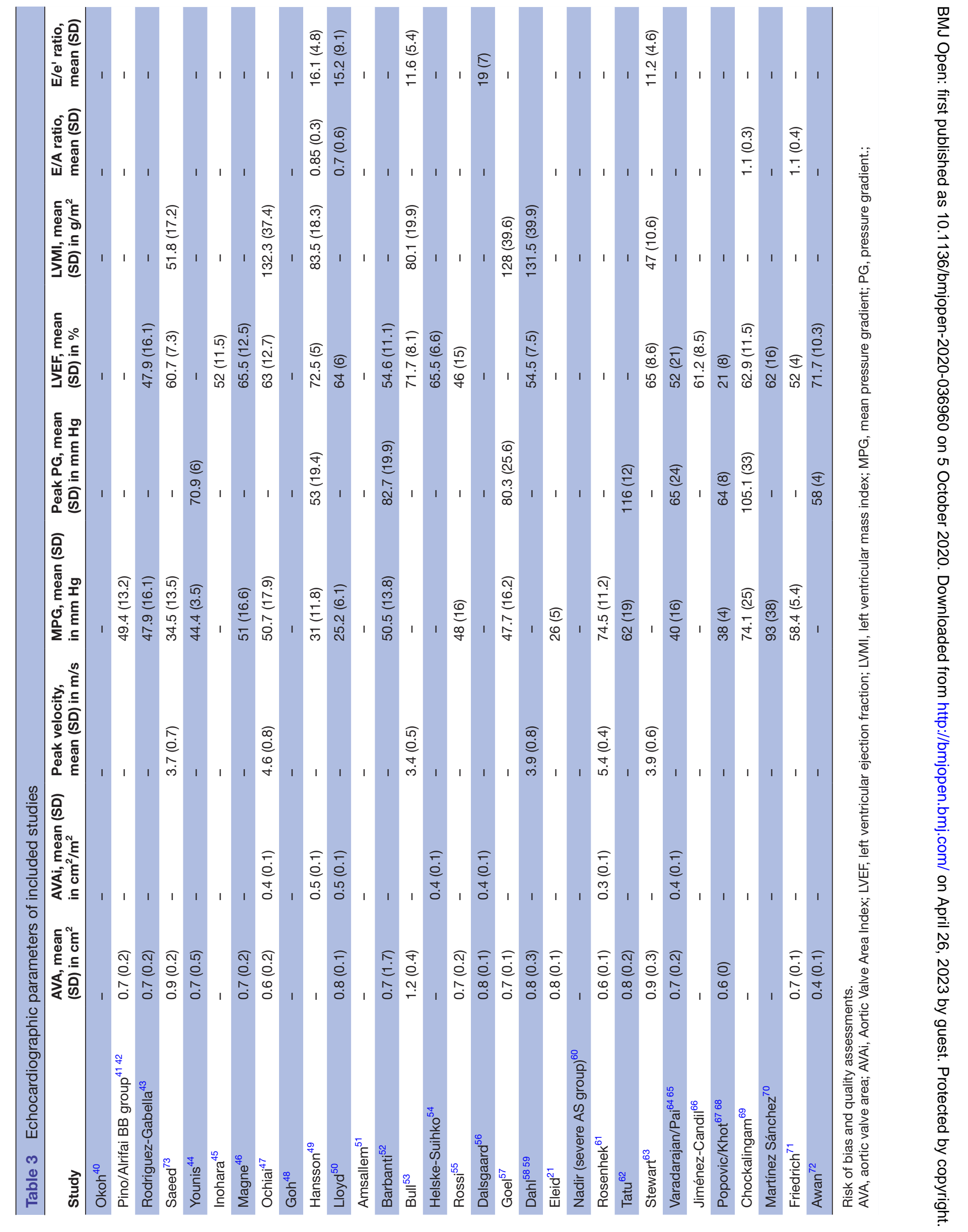


A

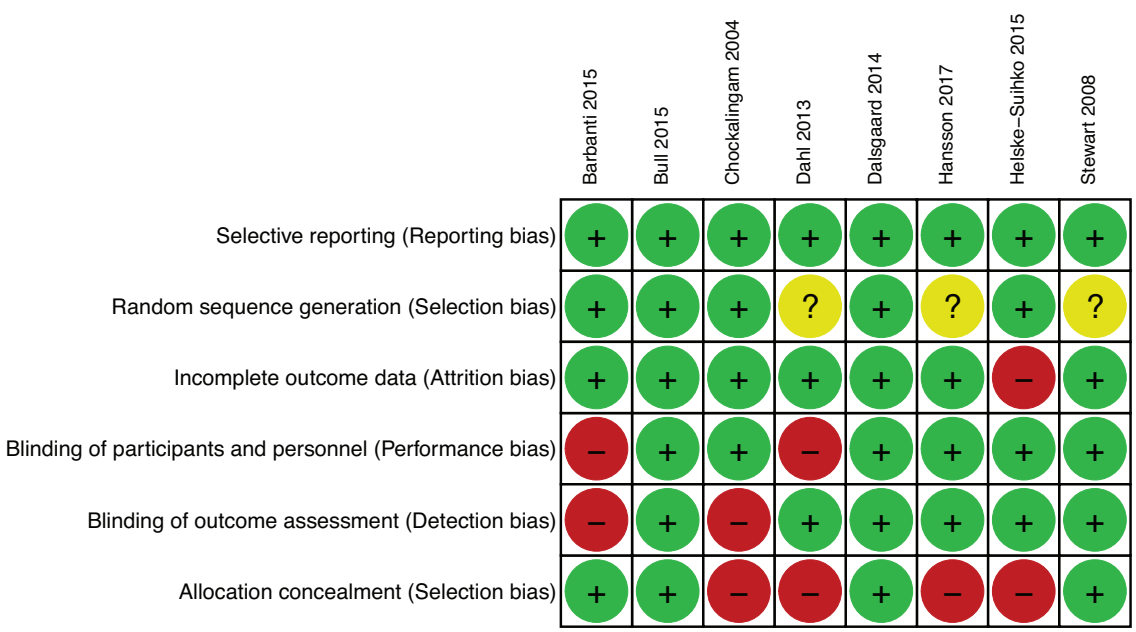

B

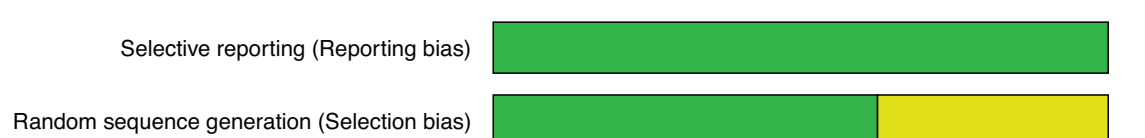

Incomplete outcome data (Attrition bias)

Blinding of participants and personnel (Performance bias)

Blinding of outcome assessment (Detection bias)

Allocation concealment (Selection bias)

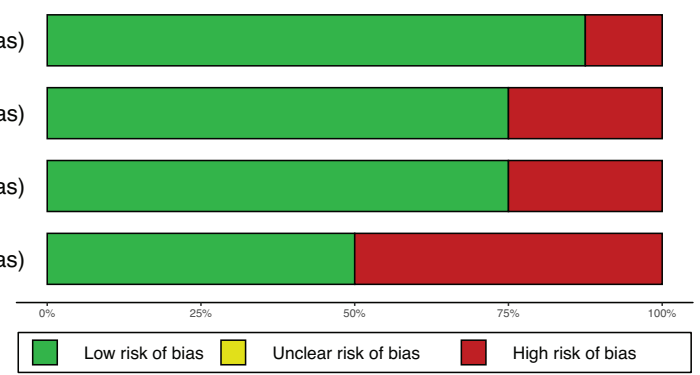

Figure 2 Risk-of-bias assessment of randomised controlled trials. Risk-of-bias summary (A) and graph (B).

severe mitral regurgitation $(12.8 \%)$ and moderate or severe aortic regurgitation $(5.1 \%)$. The mean aortic valve area was 0.7 (SD:0.3) $\mathrm{cm}^{2}$, peak velocity was 4.3 (SD:0.7) $\mathrm{m} / \mathrm{s}$, pressure gradient was 48.5 (SD:14.9) $\mathrm{mm} \mathrm{Hg}, \mathrm{LV}$ ejection fraction was $52.2 \%$ (SD:12.4\%) and LV mass index was 131.1 (SD:38.5) g/m².

\section{Risk of bias and quality assessments}

Eight studies were RCTs. Based on the Cochrane Collaboration tool, five out of eight trials had some risk of bias. However, $63 \%$ of trials had low risk of selection bias (through use of random sequence generation), $50 \%$ had low risk of selection bias (from allocation concealment), $75 \%$ had low risk of performance bias (from blinding of participants and personnel), $75 \%$ had low risk of detection bias (from blinding of outcome assessment), 88\% had low risk of attrition bias (from incomplete outcome) and $100 \%$ had low risk of reporting bias (figure 2). Most of the included studies (73\%) were observational cohort studies, and the majority were of good $(63 \%)$ or fair $(17 \%)$ quality based on the Newcastle Ottawa Scale (online supplemental materials).

\section{Primary efficacy and safety outcome: all-cause mortality}

Overall, AHT was not associated with risk of all-cause mortality (RR $0.77,95 \%$ CI 0.52 to $1.13, p=0.16$, figure 3 ) compared with no AHT or placebo in nine studies $(n=22468)^{414345-4752555773}$ with substantial heterogeneity
$\left(\mathrm{I}^{2}=85 \%, \mathrm{p}<0.01\right)$. Most studies assessed effects of RAASi and found that RAASi were associated with reduced risk of all-cause mortality (RR $0.69,95 \%$ CI 0.49 to 0.97 , $\mathrm{p}=0.04, \mathrm{I}^{2}=86.9 \%$ ) with median follow-up ranging from 1 to 5.8 years. The pooled random effect of $\mathrm{BB}$ versus without BB from two studies with median follow-up of $10-12$ months was not significantly different. ${ }^{41}{ }^{55}$ Similarly, one study did not find a difference in mortality risk between frusemide-induced diuresis with matched isotonic intravenous hydration and normal saline solution with follow-up period of 30 days. One observational study (the Exercise Testing in Aortic Stenosis (EXTAS) cohort study) found CCB was associated with increased risk of all-cause mortality (34\% in patients who received CCB vs $23 \%$ without $\mathrm{CCB}, \mathrm{p}=0.049$ ) over a median follow-up of 25 months. ${ }^{73}$ Furthermore, AHT was associated with reduced all-cause mortality after transcatheter AVR (RR $0.85,95 \%$ CI 0.79 to $0.93, \mathrm{p}=0.004, \mathrm{I}^{2}=0 \%$ ). All studies included patients with severe AS, and only one of eight studies were randomised. ${ }^{52}$

In eight observational studies that reported HRs, the pooled HR was not statistically significant, with substantial heterogeneity across studies $\left(\mathrm{I}^{2}=77 \%, \mathrm{p}<0.01\right){ }^{42-44} 47575873$ There was a statistically significant difference between drug class $(p<0.0001)$, however, only one study assessed each drug class: BB, CCB and diuretics compared with seven studies that assessed RAASi (figure 4). From studies 


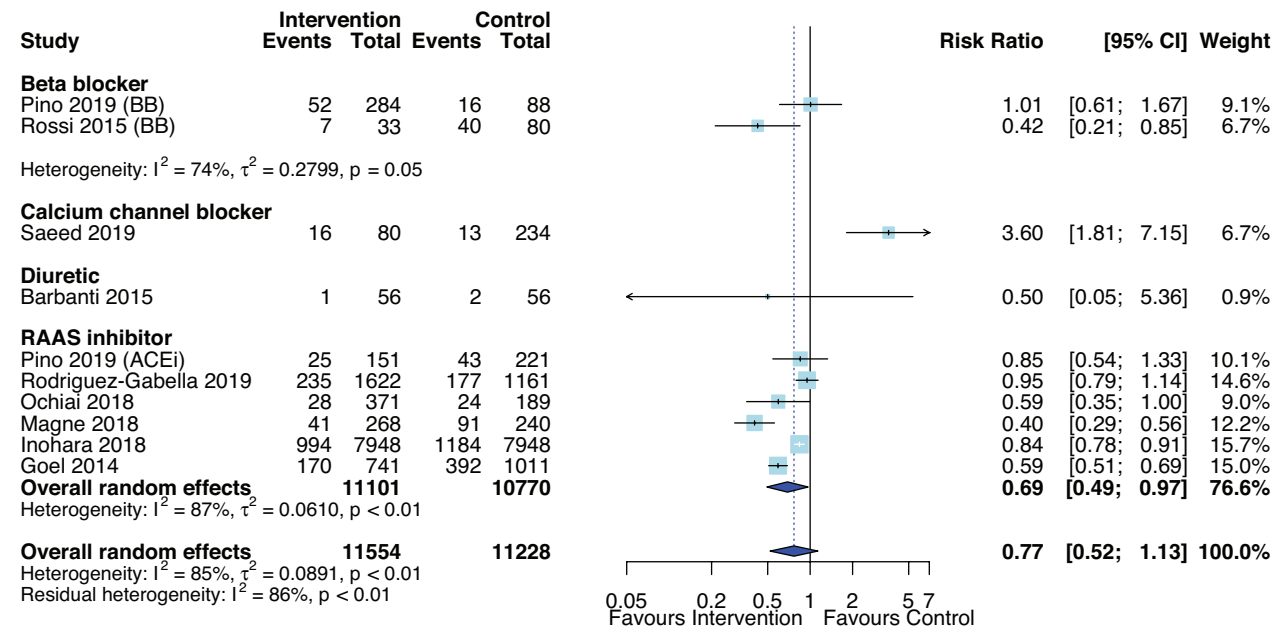

Figure 3 Forest plot of the effect of antihypertensive therapies on all-cause mortality at follow-up. ACEi, ACE inhibitor; BB, beta-blockers.

that conducted survival analyses, RAASi was also associated with reduced all-cause mortality with pooled HR of $0.58(95 \%$ CI 0.43 to $0.80, \mathrm{p}=0.006)$ with median follow-up ranging from 10 months to 5.8 years. The EXTAS study found that CCB was associated with 7-fold increased risk of all-cause mortality based on a multivariate Cox regression model. ${ }^{73}$ When stratified by mean age, AHT was significantly associated with reduced mortality in studies with mean age over 70 years (HR $0.54,95 \%$ CI 0.36 to $0.80)$. However, when stratified by LV ejection fraction by at least $50 \%$ vs over $50 \%$, there was no difference in mortality.

\section{Secondary outcomes}

AHT did not have a significant effect on change in LV mass index (standardised mean difference $=-0.80,95 \% \mathrm{CI}$ -1.86 to $0.25, \mathrm{p}=0.11$ ) or $\mathrm{LV}$ mass index at median follow-up duration ranging from 22 weeks to 1.1 years (standardised mean difference $=-0.27,95 \%$ CI -0.61 to
$0.08, \mathrm{p}=0.10)$, although there was substantial heterogeneity $\left(\mathrm{I}^{2}=93 \%\right.$ and $73 \%$, respectively) (figure 5 ). When meta-analysis was limited to only RCTs ( $5 / 6$ studies), AHT was still not significantly associated with LV mass index (standardised mean difference $=-0.91,95 \%$ CI -2.27 to $0.45, \mathrm{p}=0.14)$. Similarly, the effects of AHT on changes of systolic blood pressure (figure 6A, standardised mean difference $=-0.51,95 \% \mathrm{CI}-1.08$ to $0.07, \mathrm{p}=0.07$ ) or diastolic blood pressure (figure 6B, standardised mean difference $=-0.56,95 \% \mathrm{CI}-1.57$ to $0.46, \mathrm{p}=0.18$ ), compared with controls was not statistically significant, but favoured use of AHT. The median follow-up ranged from 49 days to 1.1 years. Meta-analyses after removing studies with short-term (49 days) follow-up ${ }^{56}$ or only including RCTs ${ }^{495} 5456$ showed consistent findings of no statistical difference in changes in blood pressures.

The effect of AHT on change of LV ejection fraction was not statistically significant (figure 7 , standardised

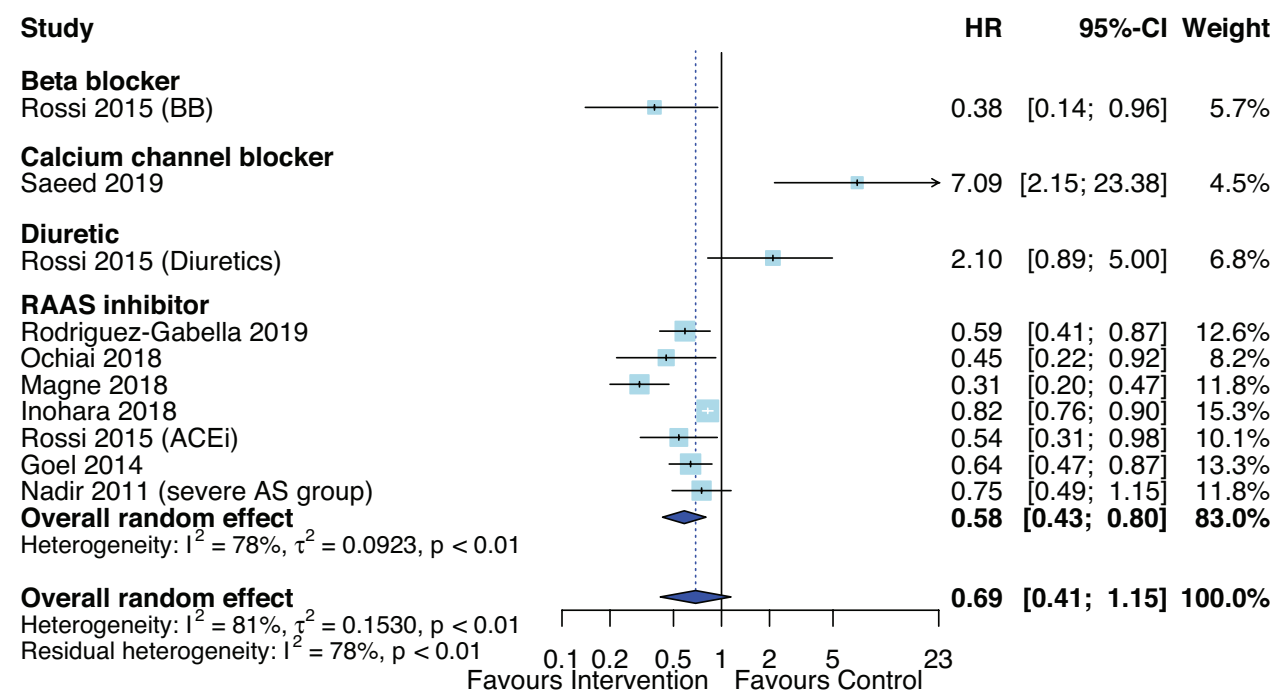

Figure 4 Forest plot of the effect of antihypertensive therapies on HR of all-cause mortality at follow-up. ACEi, ACE inhibitor; AS, aortic stenosis; RAAS, renin-angiotensin and aldosterone systems. 


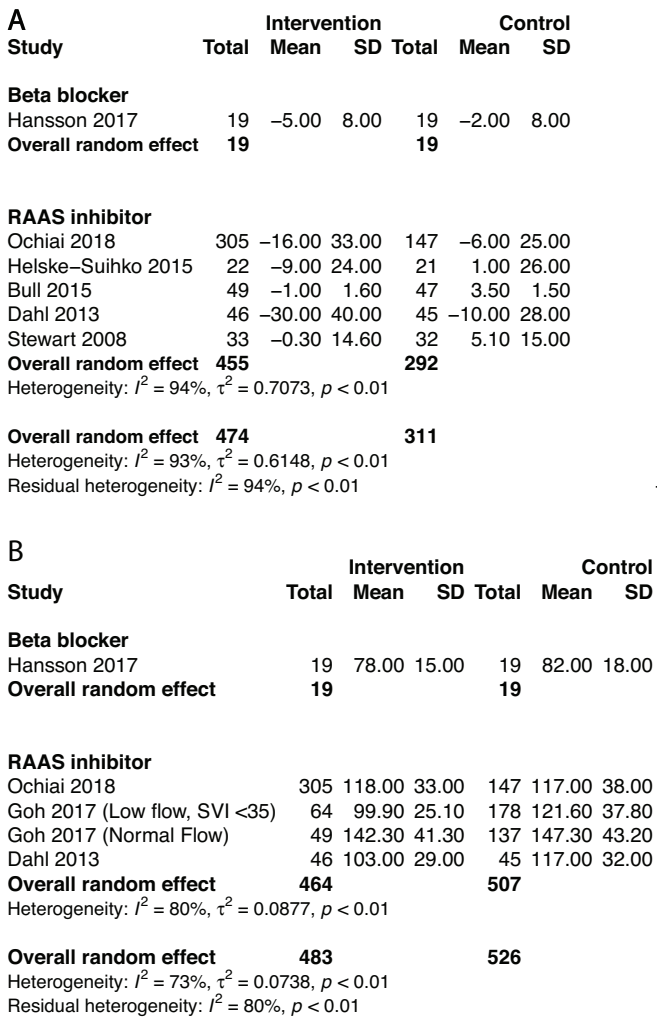

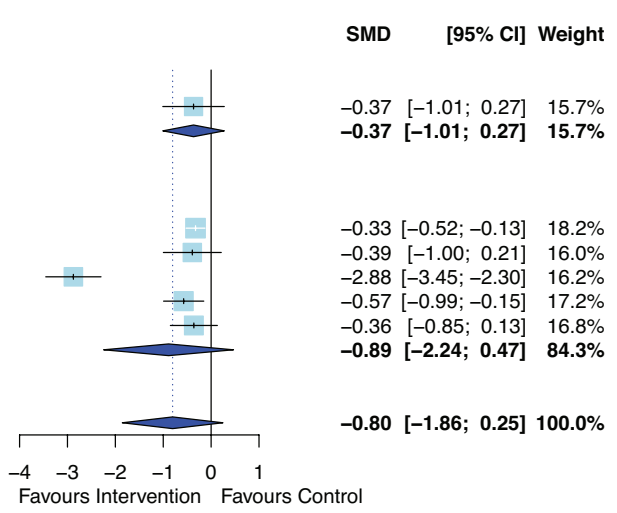

Favours Intervention Favours Control

Figure 5 Forest plot of the effect of antihypertensive therapies on (A) change in Left Ventricular Mass Index (LVMI) and (B) post-LVMI. RAAS, renin-angiotensin and aldosterone systems; SMD, standardised mean difference.

A

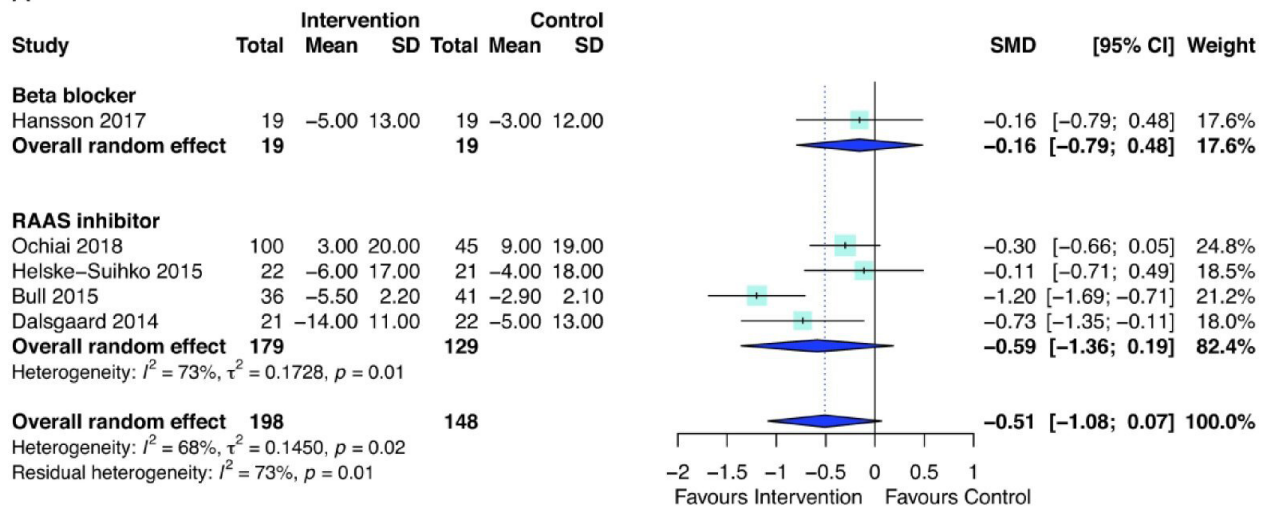

B

Study $\quad \begin{gathered}\text { Intervention } \\ \text { Control }\end{gathered}$

Beta blocker

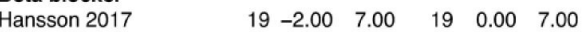

$\begin{array}{llllll}\text { Overall random effect } & \mathbf{1 9} & & \mathbf{1 9} & & \\ & & & & & \end{array}$

RAAS inhibitor

Helske-Suihko $2015 \quad 22-5.0011 .00 \quad 21-3.0011 .00$

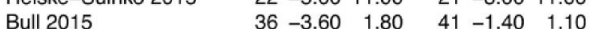

$\begin{array}{lllllll}\text { Dalsgaard } 2014 & 21 & -8.00 & 12.00 & 22 & -5.00 & 14.00 \\ \text { Overall random effect } & 79 & & \mathbf{8 4} & & \end{array}$

Overall random effect 79

Heterogeneity: $I^{2}=86 \%, \tau^{2}=0.5202, p<0.01$

Overall random effect $\quad 98$

103

Heterogeneity: $l^{2}=81 \%, \tau^{2}=0.3810, p<0.01$

Residual heterogeneity: $I^{2}=86 \%, p<0.01$

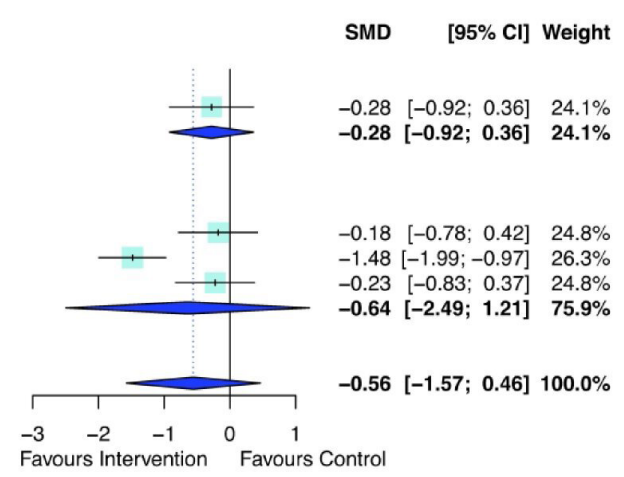

Figure 6 Forest plot of the effect of antihypertensive therapies on change in (A) systolic blood pressure and (B) diastolic blood pressure during follow-up. RAAS, renin-angiotensin and aldosterone systems; SMD, standardised mean difference. 


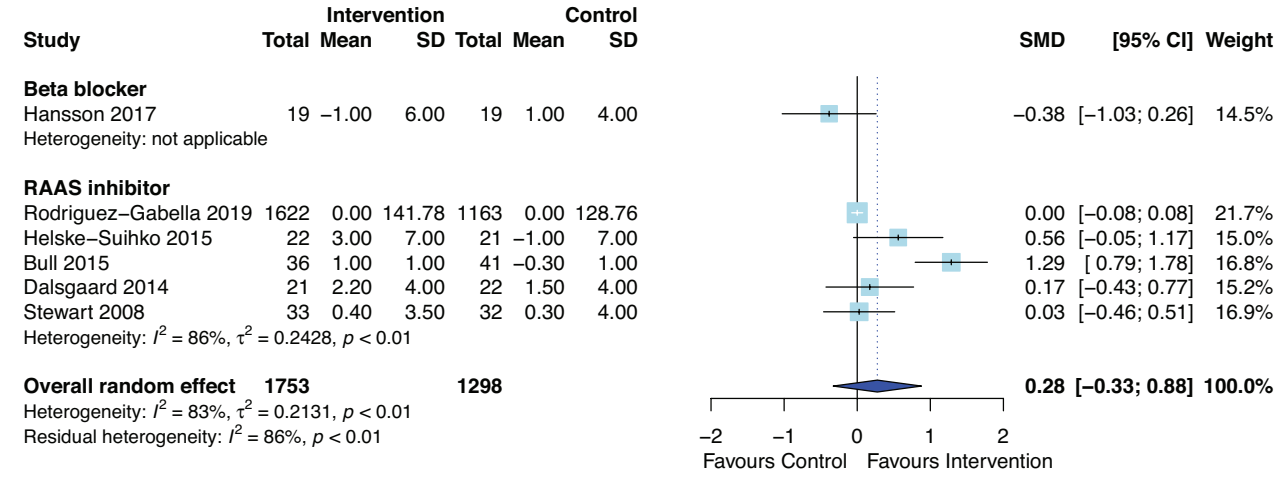

Figure 7 Forest plot of the effect of antihypertensive therapies on change in left ventricular ejection fraction during follow-up. RAAS, renin-angiotensin and aldosterone systems; SMD, standardised mean difference.

mean difference $=0.28,95 \% \mathrm{CI}-0.33$ to $0.88, \mathrm{p}=0.29$ ) with follow-up period ranging from 49 days to 3 years. When study with short term follow-up (49 days) ${ }^{56}$ was removed or only included RCTs, ${ }^{4953545663}$ results of meta-analyses were consistent and showed no difference in change in LV ejection fraction.

The Ramipril In Aortic Stenosis (RIAS) trial demonstrated a modest, but significant regression of LVH in ramipril group versus placebo group over a year (mean change in $\mathrm{LV}$ mass of $-3.9 \mathrm{vs}+4.5 \mathrm{~g}$, respectively, $\mathrm{p}=0.006$ ), which could not be explained by reduction in systolic $(\mathrm{p}=0.374)$ or diastolic blood pressures $(\mathrm{p}=0.16) .{ }^{53}$ This trial also found a trend towards reduced progression of AS, but was not statistically different (mean change in aortic valve area of $0 \mathrm{~cm}^{2}$ in ramipril group vs $-0.2 \mathrm{~cm} 2$ in placebo group, $\mathrm{p}=0.067$ ). Similarly, in another RCT, angiotensin receptor blockage with candesartan after AVR was associated with significant LVH regression compared with standard treatment (mean change in LV mass index of $-30 \mathrm{vs}-12 \mathrm{~g}$ / $\mathrm{m}^{2}, \mathrm{p}=0.015$ ), but no significant difference in change in systolic blood pressure during 12-month follow-up. ${ }^{58}$ The Optimised CathEter vAlvular iNtervention-transcatheter aortic valve implantation (TAVI) registry also showed that using propensity score-matched cohort analysis, patients with RAASi postoperatively had greater LVH regression than without (mean change in LV mass index of -9 vs $\left.-2 \mathrm{~g} / \mathrm{m}^{2}, \mathrm{p}=0.024\right)$ in 6 months post-AVR. ${ }^{47}$

\section{Safety outcomes post-AVR}

Overall, post-TAVI, the risk of acute kidney injury was not significantly lower in patients on AHT compared with controls (RR $0.80,95 \%$ CI 0.35 to $1.84, \mathrm{p}=0.47$ ), but substantial heterogeneity was demonstrated $\left(\mathrm{I}^{2}=53 \%\right)$. An RCT called the PROphylactic effect of frusemideinduCed diuresis with matched isotonic intravenous hydraTion in TAVI showed that frusemide-induced diuresis reduced incidence of acute kidney injury postTAVI, but the duration of follow-up was only 30 days. ${ }^{52}$ Furthermore, an observational study in TAVI patients found that glomerular filtration rate increased from baseline more significantly in RAASi patients $(40 \%)$ compared with non-RAASi $(29 \%)(p=0.001)$ and RAASi was independently associated with reduction in risk of development of postoperative AKI (OR 0.51, 95\% CI 0.28 to $0.91, \mathrm{p}=0.0024) .{ }^{40}$ Other outcomes such as hospital readmission $(\mathrm{p}=0.24)$, atrial fibrillation $(\mathrm{p}=0.92)$, stroke $(\mathrm{p}=0.31)$ and need for permanent pacemaker implantation $(\mathrm{p}=0.94)$ were also not statistically significant (table 4) with follow-up period ranging from 30 days to 3 years. When meta-analyses were excluded studies of less than 1-year follow-up, ${ }^{452}$ no statistical differences in outcomes were still observed.

Although some asymmetry was found in funnel plots, the publication bias appears low using Egger's tests $(p=0.14)$, and $p$ value analyses (see online supplemental materials). Of nine studies/subgroups in the mortality analysis, 4 had $\mathrm{p}$ value lower than 0.025 , and the power of the analysis was $65 \%$ (95\% CI $23.9 \%$ to $90.3 \%)$. These p curve estimates suggest that evidential value is present, and that the results are not the product of publication bias and 'p-hacking' alone.

\section{Other haemodynamic and echocardiographic changes}

Favourable outcomes such as improved haemodynamic parameters and LV function were described in some studies. However, when data were pooled in metaanalyses, there were no statistically significant differences between AHT or placebo/without AHT for mean arterial pressure (three studies with follow-up period $15 \mathrm{~min}$ to 22 weeks), heart rate (three studies with follow-up period of 49 days to 1 year), aortic valve area (three studies with follow-up period of 19 months to 3 years), mean pressure gradient (three studies with follow-up period of 3-5 months), deceleration time (three studies with follow-up period of 22 weeks to 1 year), E/A ratio (three studies with follow-up period of 3-5 months) or E/e' ratio (four studies with follow-up period of 22 weeks to 1.6 years (table 4).

\section{Other descriptive syntheses}

The effect of vasodilator (nitroprusside) infusions in patients with severe AS was only assessed in small uncontrolled observational studies. ${ }^{50} 68727475$ These studies suggest that nitroprusside can improve cardiac function by reducing afterload and LV filling pressures, and by increasing the cardiac index and stroke volume index in 
Table 4 Pooled risk ratios for postaortic valve replacement complications, haemodynamic and echocardiographic parameter changes with antihypertensive therapies at follow-up

\begin{tabular}{llccll}
\hline Postoperative complications & No of studies & Risk ratio & $\mathbf{9 5 \%} \mathbf{C l}$ & $\mathbf{P}$ value & I2 (\%) \\
\hline Postoperative atrial fibrillation & 6 & 0.98 & 0.64 to 1.50 & 0.92 & 81.2 \\
\hline Postoperative stroke or transient ischaemic attack & 4 & 0.45 & 0.06 to 3.69 & 0.31 & 86.9 \\
\hline Acute kidney injury & 3 & 0.8 & 0.35 to 1.84 & 0.47 & 53 \\
\hline Permanent pacemaker & 5 & 0.99 & 0.62 to 1.58 & 0.92 & 70 \\
\hline Readmission & 5 & 0.79 & 0.40 to 1.60 & 0.43 & 82 \\
\hline Haemodynamic and echocardiographic parameters & No of studies & $\mathbf{S M D}$ & $\mathbf{9 5 \%} \mathbf{C l}$ & $\mathbf{P}$ value & $\mathbf{I}^{\mathbf{2}}$ (\%) \\
\hline Post-mean arterial pressure & 3 & -0.62 & -2.85 to 1.60 & 0.35 & 79 \\
\hline Change in heart rate & 3 & -0.41 & -1.71 to 0.88 & 0.3 & 61 \\
\hline Post-heart rate & 3 & -0.68 & -2.60 to 1.23 & 0.26 & 80 \\
\hline Change in aortic valve area & 3 & 0.09 & -0.36 to 0.54 & 0.48 & 37 \\
\hline Post-aortic valve area & 3 & 0.01 & -0.14 to 0.16 & 0.89 & 0 \\
\hline Post-mean pressure gradient & 3 & -0.16 & -0.55 to 0.23 & 0.28 & 25 \\
\hline Post-deceleration time & 3 & 0.03 & -0.23 to 0.30 & 0.71 & 0 \\
\hline Post-E/A ratio & 3 & -0.06 & -0.43 to 0.32 & 0.67 & 23 \\
\hline Post-E/e' ratio & 4 & 0.16 & -0.56 to 0.87 & 0.54 & 65 \\
\hline
\end{tabular}

Other haemodynamic and echocardiographic changes.

$\mathrm{SMD}$, standardised mean difference.;

low-flow AS. No adverse effects were reported in patients receiving nitroprusside infusions. As such, nitroprusside can be a safe and effective bridge to AVR or long-term oral vasodilator treatment, however, patients should be monitored closely due to the potential risks of chronic, persistent vasodilation.

\section{Safety}

AHT is generally well tolerated and safe. Our meta-analysis found a statistically significant reduction in mortality when patients were treated with RAASi or when AHT was used post-AVR. A retrospective study in patients receiving a transcatheter AVR reported that BB was an independent predictor of survival and the $\mathrm{HR}$ in the absence of $\mathrm{BB}$ was 36.3 (95\% CI 4.1 to $325.2, \mathrm{p}=0.001){ }^{51}$ Two other studies reported that RAASi or BB did not affect survival. ${ }^{6165} \mathrm{In}$ contrast, the use of CCB was associated with shorter exercise time and significantly reduced survival. ${ }^{73}$ An observational, single blinded study, with randomisation of the order of drug withdrawal, demonstrated clinical benefit of ACE inhibitors through significant reduction in systolic blood pressure, increase in mean pressure gradient and reduced LV stroke work. ${ }^{66}$ Similarly, another non-controlled study showed benefit with use of captopril in patients with critical AS and heart failure through reduction in systemic vascular resistance and stroke volume, and increase in cardiac output and cardiac index..$^{70}$

\section{DISCUSSION}

\section{Clinical outcomes}

Based on pooled effect estimates from all relevant studies, this systematic review and meta-analysis provides some evidence that AHT is safe and RAASi was clinically beneficial for patients with moderate to severe AS. We demonstrated significant improvement in survival or reduction in mortality in patients receiving RAASi, although heterogeneity was substantial across studies. Subgroup analyses by drug class and AVR was conducted to investigate the heterogeneous results, however, substantial heterogeneity persisted, which may reflect more systematic nature of the studies, such as variability in study design, dose and duration of AHT, and length of follow-up across studies. There were some discrepant results in studies when interpreted in isolation as some studies failed to demonstrate significant outcomes, ${ }^{42616365}$ while others were associated with improved outcomes.

In contrast to our findings, a previous systematic review assessing the effects of renin-angiotensin system inhibitors found no significant difference in mortality, but included patients with any stage of AS severity. ${ }^{76}$ The present study, however, underscores the place of hypertension as an independent predictor of adverse cardiovascular outcomes in patients with AS. ${ }^{20} 77$ Contrary to the clinical expectations of many physicians, our data suggest that the benefit of RAASi may be most substantial in those with critical or severe AS with haemodynamic compromise.

\section{Post-AVR}

Guidelines recommend AVR in patients with severe symptomatic AS or LV dysfunction. ${ }^{31}{ }^{32}$ LV hypertrophy post-AVR has been associated with poorer postprocedural outcomes. ${ }^{7879}$ In patients with surgical or transcatheter AVR, we found a significant survival benefit, and 
reduced risk of acute kidney injury in patients receiving AHT compared with controls or placebo, despite heterogeneity. There were no significant differences in the incidence of postoperative atrial fibrillation, stroke or transient ischaemic attack, need for a permanent pacemaker or readmission rates. Current clinical trials such as the randomised multicentre phase II ARISTOTE trial assessing the effects of valsartan, an angiotensin-II receptor blocker, aim to clarify which AHT is most beneficial in moderate or severe AS. ${ }^{80}$ There is also evidence to suggest that systolic blood pressure increase significantly post-TAVI, which was shown to be associated with increase in stroke volume and cardiac output. ${ }^{81}$ There is conflicting evidence to suggest if this improves or worsens clinical outcomes. A prospective study found that patients with increased blood pressure was associated with lower risk of worsening heart failure, myocardial infarction, stroke or recurrent hospitalisation compared with stable blood pressure $(53 \%$ vs $83 \%, \mathrm{p}<0.01) .{ }^{81}$ However, another study found that persistent hypertension after TAVI was associated with reduced symptomatic improvement (increase NYHA functional class and reduced 6 min walk test). ${ }^{82}$

\section{Surrogate markers}

Interestingly, there was no favourable reduction in LV mass index, systolic or diastolic blood pressures in patients with AHT, compared with controls or placebo. Other haemodynamic or echocardiographic parameters did not differ significantly between those who were prescribed AHT and those who were not, however, pooled data were limited by substantial heterogeneity, variability in measurements, differences in follow-up periods and patient characteristics. Evidence was also mostly derived from non-randomised trials and randomised trials with small sample sizes.

The results also show that different AHT have varying impact on LV function and clinical outcomes. ${ }^{54} 5508384$ Some authors attribute the benefits of AHT in this context to reduction in haemodynamic stress and myocardial ischaemia and to reduction in heart failure symptoms. ${ }^{55} 85$ Haemodynamic factors and neurohormonal systems such as the RAAS are implicated in LV hypertrophy and myocardial fibrosis in AS. ${ }^{86} 87$ There remains a need for future studies to establish an appropriate blood pressure target and to clarify the optimum dosing, initiation time frame and duration of treatment with AHT for patients with moderate or severe AS. Most studies included in our meta-analysis assessed the effects of RAASi. There are insufficient data to compare clinical outcomes between drug classes and to evaluate whether a particular drug class is clinically superior in patients with moderate or severe AS.

\section{CONCLUSION}

This is the first systematic review and meta-analysis to show that RAASi appears to have a clinical benefit in patients with moderate or severe AS, but is limited by the small number of studies and substantial heterogeneity. The included randomised trials were generally of good quality, but not all RCTs reported all outcomes relevant to this review and only one study reported all-cause mortality. ${ }^{52}$ Nevertheless, improved survival compared with control/placebo was demonstrated in these patients, especially in those who had a transcatheter AVR. Further studies with clear inclusion and exclusion criteria, longer term follow-up and reporting of clinical outcomes are needed before stronger policies are recommended for AHT use in patients with moderate or severe AS. RCTs with an appropriate sample size are required in order to determine which AHT is optimum in patients with moderate or severe AS.

Acknowledgements We thank Evelyn Hutcheon of the Western Health Library for assistance with literature search strategies.

Contributors TM conceived this review. JS and TM designed the protocol. JS and EC performed the literature search, study selection, data extraction and critical appraisal of the articles. Conflicts were resolved with discussion with TM. JS and EC synthesised the data. JS wrote the first draft of the manuscript. All authors (JS, $\mathrm{EC}, \mathrm{CN}$ and TM) revised the paper and approved the final version. TM is the study guarantor, responsible for overall content of the manuscript.

Funding This work has been supported in part by a Partnership grant (1149692) from the National Health and Medical Research Council, Canberra. JS was supported by scholarships from the National Heart Foundation of Australia (ID: 102578), National Health and Medical Research Council of Australia (ID: 1191044).

Competing interests All authors have completed the ICMJE uniform disclosure form at www.icmje.org/coi_disclosure.pdf and declare: support from Australian Government Research Training Program (Research Scholarship) for the submitted work; no financial relationships with any organisations that might have an interest in the submitted work in the previous three years; no other relationships or activities that could appear to have influenced the submitted work.

Patient and public involvement Patients and/or the public were not involved in the design, or conduct, or reporting, or dissemination plans of this research.

Patient consent for publication Not required.

Ethics approval Not required.

Provenance and peer review Not commissioned; externally peer reviewed. Data availability statement Data are available on reasonable request.

Open access This is an open access article distributed in accordance with the Creative Commons Attribution Non Commercial (CC BY-NC 4.0) license, which permits others to distribute, remix, adapt, build upon this work non-commercially, and license their derivative works on different terms, provided the original work is properly cited, appropriate credit is given, any changes made indicated, and the use is non-commercial. See: http://creativecommons.org/licenses/by-nc/4.0/.

ORCID iD

Thomas Marwick http://orcid.org/0000-0001-9065-0899

\section{REFERENCES}

1 Benjamin EJ, Muntner P, Alonso A, et al. Heart disease and stroke statistics-2019 update: a report from the American heart association. Circulation 2019;139:e56-28.

2 Badiani S, van Zalen J, Treibel TA, et al. Aortic stenosis, a left ventricular disease: insights from advanced imaging. Curr Cardiol Rep 2016;18:80.

3 Ito S, Miranda WR, Nkomo VT, et al. Reduced left ventricular ejection fraction in patients with aortic stenosis. J Am Coll Cardiol 2018;71:1313-21.

4 Grossman W, Jones D, McLaurin LP. Wall stress and patterns of hypertrophy in the human left ventricle. J Clin Invest 1975;56:56-64.

5 Carabello BA, Paulus WJ. Aortic stenosis. Lancet 2009;373:956-66.

6 Gould KL, Carabello BA. Why angina in aortic stenosis with normal coronary arteriograms? Circulation 2003;107:3121-3. 
7 Levy D. Clinical significance of left ventricular hypertrophy: insights from the Framingham study. J Cardiovasc Pharmacol 1991;17:S1-6.

8 Gaasch WH, Zile MR, Hoshino PK, et al. Tolerance of the hypertrophic heart to ischemia. Studies in compensated and failing dog hearts with pressure overload hypertrophy. Circulation 1990;81:1644-53.

9 Zile MR, Brutsaert DL. New concepts in diastolic dysfunction and diastolic heart failure: Part II: causal mechanisms and treatment. Circulation 2002;105:1503-8.

10 Rajappan K, Rimoldi OE, Camici PG, et al. Functional changes in coronary microcirculation after valve replacement in patients with aortic stenosis. Circulation 2003;107:3170-5.

11 Kupari M, Turto H, Lommi J. Left ventricular hypertrophy in aortic valve stenosis: preventive or promotive of systolic dysfunction and heart failure? Eur Heart $J$ 2005;26:1790-6.

12 Schwartz LS, Goldfischer J, Sprague GJ, et al. Syncope and sudden death in aortic stenosis. Am J Cardiol 1969;23:647-58.

13 Omran H, Fehske W, Rabahieh R, et al. Relation between symptoms and profiles of coronary artery blood flow velocities in patients with aortic valve stenosis: a study using transoesophageal doppler echocardiography. Heart 1996;75:377-83.

14 Julius BK, Spillmann M, Vassalli G, et al. Angina pectoris in patients with aortic stenosis and normal coronary arteries. mechanisms and pathophysiological concepts. Circulation 1997:95:892-8.

15 Gould KL. Why angina pectoris in aortic stenosis. Circulation 1997; $95: 790-2$

16 Faggiano P, Rusconi C, Sabatini T, et al. Congestive heart failure in patients with valvular aortic stenosis. A clinical and echocardiographic Doppler study. Cardiology 1995;86:120-9.

17 Pellikka PA, Sarano ME, Nishimura RA, et al. Outcome of 622 adults with asymptomatic, hemodynamically significant aortic stenosis during prolonged follow-up. Circulation 2005;111:3290-5.

18 Rossi A, Tomaino M, Golia G, et al. Echocardiographic prediction of clinical outcome in medically treated patients with aortic stenosis. Am Heart J 2000;140:766-71.

19 Hueb JC, Vicentini JTR, Roscani MG, et al. Impact of hypertension on ventricular remodeling in patients with aortic stenosis. Arq Bras Cardiol 2011;97:254-9.

20 Rieck ÅE, Cramariuc D, Boman K, et al. Hypertension in aortic stenosis: implications for left ventricular structure and cardiovascular events. Hypertension 2012;60:90-7.

21 Eleid MF, Nishimura RA, Sorajja P, et al. Systemic hypertension in low-gradient severe aortic stenosis with preserved ejection fraction. Circulation 2013;128:1349-53.

22 Carabello BA, Paulus WJ. Aortic stenosis. Lancet 2009;373:956-66.

23 Lindman BR, Otto CM. Time to treat hypertension in patients with aortic stenosis. Circulation 2013;128:1281-3.

24 Rodés-Cabau J, Webb JG, Cheung A, et al. Transcatheter aortic valve implantation for the treatment of severe symptomatic aortic stenosis in patients at very high or prohibitive surgical risk: acute and late outcomes of the multicenter Canadian experience. J Am Coll Cardiol 2010;55:1080-90.

25 Bennett JE, Stevens GA, Mathers CD, et al. Ncd countdown 2030: worldwide trends in non-communicable disease mortality and progress towards sustainable development goal target 3.4. Lancet 2018;392:1072-88.

26 Gulland A. Global life expectancy increases by five years. BMJ 2016;353:i2883.

27 Li J, Kinfu Y. Impact of socioeconomic and risk factors on cardiovascular disease and type II diabetes in Australia: comparison of results from longitudinal and cross-sectional designs. BMJ Open 2016;6:e010215.

28 Antonini-Canterin F, Huang G, Cervesato E, et al. Symptomatic aortic stenosis: does systemic hypertension play an additional role? Hypertension 2003;41:1268-72.

29 Jolobe OM. Systolic hypertension is also the neglected stepsister of aortic stenosis. Am J Med 2008;121:e21.

30 Herrmann S, Störk S, Niemann M, et al. Low-gradient aortic valve stenosis myocardial fibrosis and its influence on function and outcome. J Am Coll Cardiol 2011;58:402-12.

31 Baumgartner H, Falk V, Bax JJ, et al. 2017 ESC/EACTS guidelines for the management of valvular heart disease. Eur Heart $J$ 2017;38:2739-91.

32 Nishimura RA, Otto CM, Bonow RO, et al. 2014 AHA/ACC guideline for the management of patients with valvular heart disease: executive summary: a report of the American college of cardiology/American heart association task force on practice guidelines. J Am Coll Cardiol 2014;63:2438-88.

33 Morgan HE, Baker KM. Cardiac hypertrophy. mechanical, neural, and endocrine dependence. Circulation 1991;83:13-25.
34 Bregagnollo EA, Okoshi K, Bregagnollo IF, et al. [Effects of the prolonged inhibition of the angiotensin-converting enzyme on the morphological and functional characteristics of left ventricular hypertrophy in rats with persistent pressure overload]. Arq Bras Cardiol 2005;84:225-32.

35 Moher D, Liberati A, Tetzlaff J, et al. Preferred reporting items for systematic reviews and meta-analyses: the PRISMA statement. PLoS Med 2009;6:e1000097.

36 Stroup DF, Berlin JA, Morton SC, et al. Meta-analysis of observational studies in epidemiology: a proposal for reporting. meta-analysis of observational studies in epidemiology (moose) group. JAMA 2000;283:2008-12.

37 Higgins JPT, Thomas J, Chandler J, et al. 10.10.2 identifying and measuring heterogeneity. Cochrane handbook for systematic reviews of interventions version 60 (updated July 2019): cochrane, 2019.

38 Simonsohn U, Nelson LD, Simmons JP. And effect size: correcting for publication bias using only significant results. perspectives on psychological science. Los Angeles, CA: Sage Publications, 2014: 666-81.

$39 \mathrm{R}$ Core Team. R: a language and environment for statistical computing. Vienna, Austria: R Foundation for Statistical Computing, 2019.

40 Okoh A, Singh S, Aggarwal S, et al. Renin-angiotensin-aldosterone system inhibitors are associated with reno-protective effects in aging patients undergoing transcatheter aortic valve replacement. Catheter Cardiovasc Interv 2019;93:S229-30.

41 Pino JE, Ramos Tuarez F, Torres P, et al. Neuroendocrine inhibition in patients with heart failure and severe aortic stenosis undergoing TAVI. Europ J Heart Fail 2019;21:244.

42 Alrifai A, Sundaravel S, Grajeda E, et al. The impact of beta blockers on transcatheter aortic valve replacement outcomes. JACC: Cardiovas Intervent 2018;11:S48.

43 Rodriguez-Gabella T, Catalá P, Muñoz-García AJ, et al. Reninangiotensin system inhibition following transcatheter aortic valve replacement. J Am Coll Cardiol 2019;74:631-41.

44 Younis A, Orvin K, Nof E, et al. The effect of periprocedural beta blocker withdrawal on arrhythmic risk following transcatheter aortic valve replacement. Catheter Cardiovasc Interv 2019;93:1361-6.

45 Inohara T, Manandhar P, Kosinski AS, et al. Association of reninangiotensin inhibitor treatment with mortality and heart failure readmission in patients with transcatheter aortic valve replacement JAMA 2018;320:2231-41.

46 Magne J, Guinot B, Le Guyader A, et al. Relation between reninangiotensin system blockers and survival following isolated aortic valve replacement for aortic stenosis. Am J Cardiol 2018;121:455-60.

47 Ochiai T, Saito S, Yamanaka F, et al. Renin-angiotensin system blockade therapy after transcatheter aortic valve implantation. Heart 2018;104:644-51.

48 Goh SS-N, Sia C-H, Ngiam NJ, et al. Effect of renin-angiotensin blockers on left ventricular remodeling in severe aortic stenosis. Am J Cardiol 2017;119:1839-45.

49 Hansson NH, Sörensen J, Harms HJ, et al. Metoprolol reduces hemodynamic and metabolic overload in asymptomatic aortic valve stenosis patients: a randomized trial. Circ Cardiovasc Imaging 2017:10:10

50 Lloyd JW, Nishimura RA, Borlaug BA, et al. Hemodynamic response to nitroprusside in patients with Low-Gradient severe aortic stenosis and preserved ejection fraction. J Am Coll Cardiol 2017;70:1339-48.

51 Amsallem M, Bouleti C, Himbert D, et al. 0093: early and late outcomes after trans-catheter aortic valve implantation in patients with previous thoracic irradiation. Arch Cardiovas Dis Suppl 2016;8:58.

52 Barbanti M, Gulino S, Capranzano P, et al. Acute kidney injury with the RenalGuard system in patients undergoing transcatheter aortic valve replacement: the PROTECT-TAVI trial (prophylactic effecT of Frusemide-induCed diuresis with matched isotonic intravenous hydraTion in transcatheter aortic valve implantation). JACC: Cardiovas Interven 2015;8:1595-604.

53 Bull S, Loudon M, Francis JM, et al. A prospective, double-blind, randomized controlled trial of the angiotensin-converting enzyme inhibitor ramipril in aortic stenosis (RIAS trial). Eur Heart $J$ Cardiovasc Imaging 2015;16:834-41.

54 Helske-Suihko S, Laine M, Lommi J, et al. Is blockade of the reninangiotensin system able to reverse the structural and functional remodeling of the left ventricle in severe aortic stenosis? $J$ Cardiovasc Pharmacol 2015;65:233-40.

55 Rossi A, Temporelli PL, Cicoira M, et al. Beta-blockers can improve survival in medically-treated patients with severe symptomatic aortic stenosis. Int J Cardiol 2015;190:15-17.

56 Dalsgaard M, Iversen K, Kjaergaard J, et al. Short-term hemodynamic effect of angiotensin-converting enzyme inhibition in patients with 
severe aortic stenosis: a placebo-controlled, randomized study. Am Heart J 2014;167:226-34.

57 Goel SS, Aksoy O, Houghtaling P, et al. TCT-750 role of reninangiotensin system blockade therapy following aortic valve replacement for severe aortic stenosis. J Am Coll Cardiol 2014;64:B219.

58 Dahl JS, Videbæk L, Poulsen MK, et al. Prevention of atrial fibrillation in patients with aortic valve stenosis with candesartan treatment after aortic valve replacement. Int J Cardiol 2013;165:242-6.

59 Dahl JS, Videbaek L, Poulsen MK, et al. Effect of candesartan treatment on left ventricular remodeling after aortic valve replacement for aortic stenosis. Am J Cardiol 2010;106:713-9.

60 Nadir MA, Wei L, Elder DHJ, et al. Impact of renin-angiotensin system blockade therapy on outcome in aortic stenosis. J Am Coll Cardiol 2011;58:570-6.

61 Rosenhek R, Zilberszac R, Schemper M, et al. Natural history of very severe aortic stenosis. Circulation 2010;121:151-6.

62 Tatu A, Broasca M, Munteanu I, et al. The efficacy of telmisartan and carvedilol in the left ventricle systolic and diastolic dysfunction recovery in patients with aortic valve replacement for aortic stenosis. Interact Cardiovas Thor Surg 2009;8:S102-3.

63 Stewart RAH, Kerr AJ, Cowan BR, et al. A randomized trial of the aldosterone-receptor antagonist eplerenone in asymptomatic moderate-severe aortic stenosis. Am Heart J 2008;156:348-55.

64 Pai RG, Kapoor N, Bansal RC, et al. Malignant natural history of asymptomatic severe aortic stenosis: benefit of aortic valve replacement. Ann Thorac Surg 2006;82:2116-22.

65 Varadarajan P, Kapoor N, Bansal RC, et al. Clinical profile and natural history of 453 nonsurgically managed patients with severe aortic stenosis. Ann Thorac Surg 2006;82:2111-5.

66 Jiménez-Candil J, Bermejo J, Yotti R, et al. Effects of angiotensin converting enzyme inhibitors in hypertensive patients with aortic valve stenosis: a drug withdrawal study. Heart 2005;91:1311-8.

67 Khot UN, Novaro GM, Popović ZB, et al. Nitroprusside in critically ill patients with left ventricular dysfunction and aortic stenosis. $N$ Engl J Med 2003;348:1756-63.

68 Popović ZB, Khot UN, Novaro GM, et al. Effects of sodium nitroprusside in aortic stenosis associated with severe heart failure: pressure-volume loop analysis using a numerical model. Am J Physiol Heart Circ Physiol 2005;288:H416-23.

69 Chockalingam A, Venkatesan S, Subramaniam T, et al. Safety and efficacy of angiotensin-converting enzyme inhibitors in symptomatic severe aortic stenosis: symptomatic cardiac obstruction-pilot study of enalapril in aortic stenosis (SCOPE-AS). Am Heart J 2004;147:E19.

70 Martínez Sánchez C, Henne O, Arceo A, et al. [Hemodynamic effects of oral captopril in patients with critical aortic stenosis]. Arch Inst Cardiol Mex 1996;66:322-30.

71 Friedrich SP, Lorell BH, Rousseau MF, et al. Intracardiac angiotensinconverting enzyme inhibition improves diastolic function in patients with left ventricular hypertrophy due to aortic stenosis. Circulation 1994;90:2761-71.

72 Awan NA, DeMaria AN, Miller RR, et al. Beneficial effects of nitroprusside administration on left ventricular dysfunction and myocardial ischemia in severe aortic stenosis. Am Heart $J$ 1981;101:386-94.

73 Saeed S, Mancia G, Rajani R, et al. Antihypertensive treatment with calcium channel blockers in patients with moderate or severe aortic stenosis: relationship with all-cause mortality. Int J Cardiol 2020;298:122-5.

74 Eleid M, Nishimura R, Borlaug B, et al. Acute hemodynamic effects of sodium nitroprusside in low gradient severe aortic stenosis with preserved ejection fraction. J Am Coll Cardiol 2013;61:E2114.

75 Khot UN, Novaro GM, Popović ZB, et al. Nitroprusside in critically ill patients with left ventricular dysfunction and aortic stenosis. $N$ Engl J Med Overseas Ed 2003;348:1756-63.

76 Andersson C, Abdulla J. Is the use of renin-angiotensin system inhibitors in patients with aortic valve stenosis safe and of prognostic benefit? A systematic review and meta-analysis. Eur Heart $J$ Cardiovasc Pharmacother 2017;3:21-7.

77 Capoulade R, Clavel M-A, Mathieu P, et al. Impact of hypertension and renin-angiotensin system inhibitors in aortic stenosis. Eur J Clin Invest 2013;43:1262-72.

78 Orsinell DA, Aurigemma GP, Battista S, et al. Left ventricular hypertrophy and mortality after aortic valve replacement for aortic stenosis. J Am Coll Cardiol 1993;22:1679-83.

79 Zybach-Benz RE, Aeschbacher BC, Schwerzmann M. Impact of left ventricular hypertrophy late after aortic valve replacement for aortic stenosis on cardiovascular morbidity and mortality. Int $J$ Cardiol 2006;109:41-7.

80 Efficacy of angiotensin receptor blocker following aortlc valve intervention for aortlc stenosis: a randomized mulTi-cEntric doubleblind phase II study, 2017. Available: Https://clinicaltrialsgov/show/ nct03315832

81 Perlman GY, Loncar S, Pollak A, et al. Post-procedural hypertension following transcatheter aortic valve implantation: incidence and clinical significance. JACC Cardiovasc Interv 2013;6:472-8.

82 Reinthaler M, Stähli BE, Gopalamurugan AB, et al. Postprocedural arterial hypertension: implications for clinical outcome after transcatheter aortic valve implantation. J Heart Valve Dis 2014;23:675-82

83 Routledge HC, Ong KR, Townend JN. Left ventricular hypertrophy and aortic stenosis: a possible role for ACE inhibition? British Journal of Cardiology 2003;10:214-6.

84 Bang CN, Greve AM, Køber L, et al. Renin-angiotensin system inhibition is not associated with increased sudden cardiac death, cardiovascular mortality or all-cause mortality in patients with aortic stenosis. Int J Cardiol 2014;175:492-8.

85 Kang TS, Park S. Antihypertensive treatment in severe aortic stenosis. J Cardiovasc Imaging 2018;26:45-53.

86 Grimm D, Huber M, Jabusch HC, et al. Extracellular matrix proteins in cardiac fibroblasts derived from rat hearts with chronic pressure overload: effects of beta-receptor blockade. J Mol Cell Cardiol 2001;33:487-501.

87 Katsi V, Georgiopoulos G, Oikonomou D, et al. Aortic stenosis, aortic regurgitation and arterial hypertension. Curr Vasc Pharmacol 2019;17:180-90. 